\title{
Impact Study on Power Generation from Photovoltaic System due to Change in Local Irradiance and Temperature at Kathmandu Valley, Nepal
}

\author{
Manish Shrestha, Nawraj Bhattarai \\ Department of Mechanical Engineering, Pulchowk Campus, Institute of engineering \\ Tribhuvan University, Kathmandu, Nepal \\ Corresponding author: bnawraj@gmail.com,ma.shrestha0@gmail.com
}

Received: March 7, 2016 Revised: July 4, 2016 Accepted: July 15, 2016

\begin{abstract}
Solar Photovoltaic system has become popular among the renewable energy due to free availability and low maintenance costs. Economically, the decreasing cost from continuous development adds another motive for the use of photovoltaic system. There has been a continuous study regarding the estimation on output of the photovoltaic system, in normal operating conditions. The output is subject to variations due to various environmental factors. The aim of this study is to evaluate how Design of Experiments (DoE) Method is used to model the impact of meteorological data on the electric power generated by the photovoltaic system. In this paper, the simulation and experiment based analysis has been presented and the degree of impact of irradiance and temperature on the output power of the photovoltaic module has been illustrated.
\end{abstract}

Keywords: Photovoltaic, Irradiance, Temperature, Design of Experiments (DoE)

\section{Introduction}

Photovoltaic cells used for providing energy supplement has been accelerated in the last few decades. This has been boosted by environmental awareness all around. Economically the decreasing cost from continuous development adds another motive for the use of photovoltaic technology. The use has migrated from remote locations to the grid applications to satisfy the ever increasing energy demands. The performance of this technology depends on the availability of solar irradiance at the corresponding location and local temperature [16].

The irradiance affects primarily the amount of current produced and is of the primary concern. The light intensity absorbed is affected by weather patterns and air mass. The cell temperature affects the voltage produced. As the cell temperature increases, the current produced increases slightly the same but the voltage is reduced, reducing the output power. These factors need been taken in consideration to accurately predict the energy production. The solar panel orientation must be optimum for maximum energy generation. Under non optimal placement the incidence angle will be large decreasing the energy that can be absorbed. The design procedure must take in account all these to predict the energy production. It is important to characterize the response of the system so the equipment associated with the PV panel can be sized appropriately. 
Photovoltaic system designers follow the specifications provided by the manufacturers for system design purposes. Instead of relying on manufacturer's data for the design and evaluation of the plant, practical models have been developed for the prediction of energy production. These studies provide an approximation of operational data with various levels of error $[1,9,16]$.

These studies make the best estimate on the performances of the photovoltaic system at any given location concurrent with the weather conditions. These studies were developed to estimate the output on field condition provide insights on the DC output performance on similar geographical locations.

There has been a lot of analysis on the influence of environmental factors on the output of photovoltaic modules. Some techniques focus on the effect on the output current and voltage as the function of varying irradiance as shown by Kerr and Cuevas [8], while some techniques focus the effect of temperature on the performance of PV modules. There are also various models regarding the efficiency and power. These are based on the varying environmental conditions. The models point out the effect of different factors on the corresponding test sites. The complexity of the model is determined by the relevant parameter chosen during the study $[10,4,7]$.

\section{Irradiance}

The sun delivers its energy to us in two main forms: heat and light. There are two main types of solar power systems, namely, solar thermal systems that trap heat in suitable materials, and solar PV systems that convert sunlight directly into electricity. PV cells are made of light-sensitive semiconductor materials that use photons to dislodge electrons to drive an electric current [6].

The primary constitutions for solar cells are the semiconductors, which have weakly bonded electrons occupying a band of energy called the valance band. When energy exceeding a certain threshold, called band gap energy, is applied to a valance electron, the bonds are broken and the electron is free to move around in a new energy band called the conduction band where it can conduct electricity through the material. The effect of Irradiance on the photovoltaic module is shown in Fig. 1 and Fig. 2.

\section{Temperature}

The temperature of operation of a PV module is determined by the law of conservation of energy. The solar energy that is absorbed by a module is converted partly into thermal energy and partly into electrical energy which is removed from the cell through the external circuit [3].

The temperature of a photovoltaic module is a key parameter for the accurate assessment of its performance. Module efficiency decreases significantly from efficiency ratings obtained at standard operating conditions based on measurements at $25^{\circ} \mathrm{C}$. While temperature effects are secondary to the influence of incident radiation, accurate measurements and estimates of the cell/ module temperature are needed to accurately estimate photovoltaic (PV) system performance and to appropriately manage PV system output.

In a solar cell, the parameter most affected by an increase in temperature is the open-circuit voltage. The voltage offered by the solar cell is the band gap voltage of the device. A crystalline silicon solar cell thus has a operating voltage of around 0.7 volts. The increase in temperature thus reduces the effective voltage while increasing the current due to electron mobility [17]. The impact of increasing temperature is shown in the Fig. 1 and Fig. 2. 


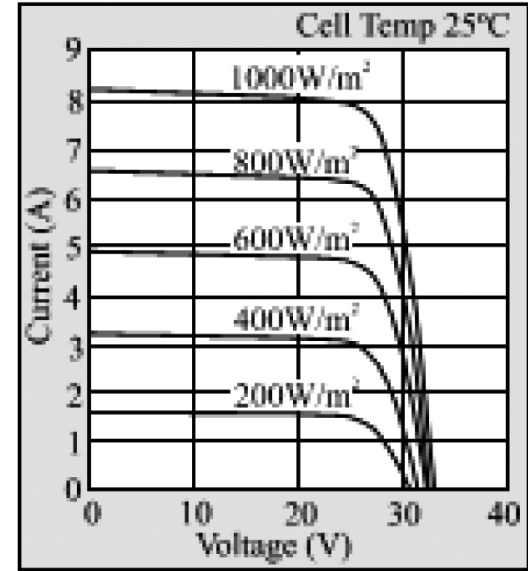

(a)

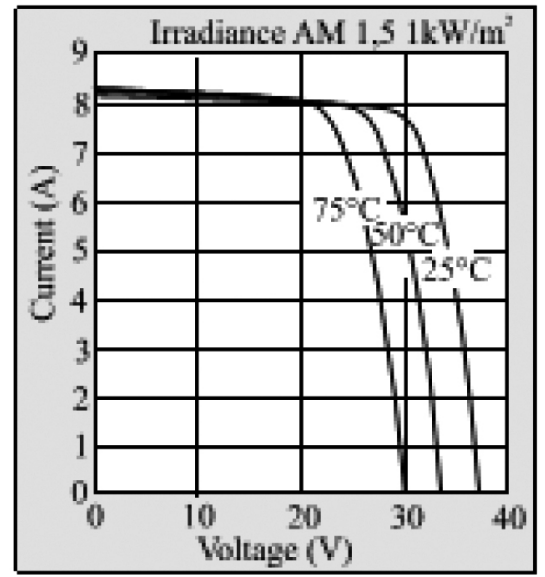

(b)

Fig. 1: I-V curve from Kyocera KC200GT PV module: (a) under constant temperature and (b) under constant irradiance

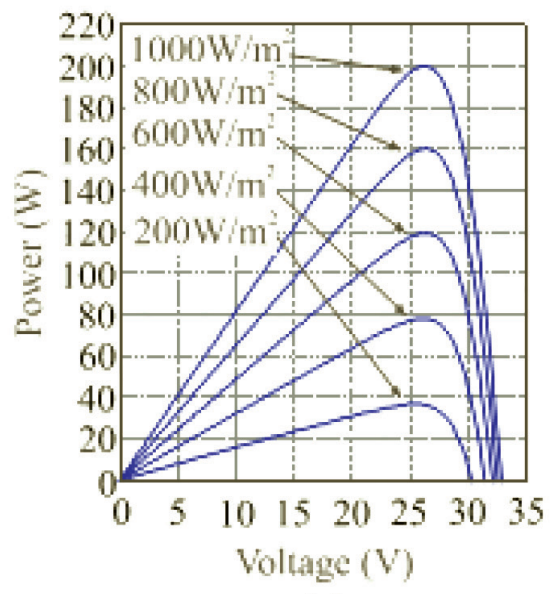

(a)

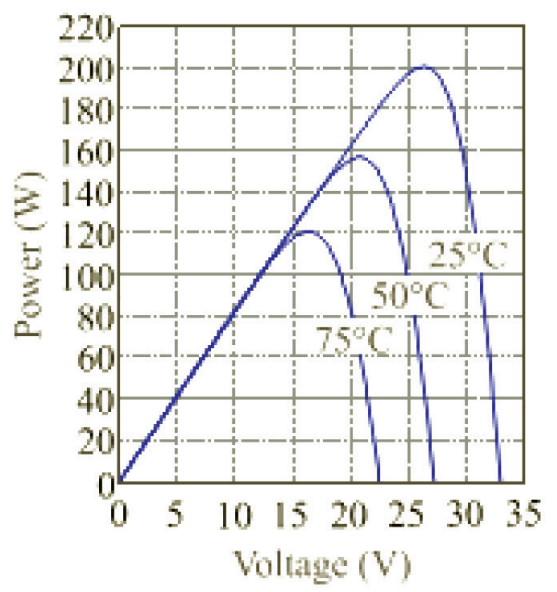

(b)

Fig. 2: P-V curve from Kyocera KC200GT PV module: (a) under constant temperature and (b) under constant solar radiation

\section{Experimental Setup}

The experiment was conducted on the roof of a building in the premises of Institute of Engineering, Tribhuvan University, Lalitpur, Nepal. The experiment was conducted from 13th August 2015 to 10th January 2016. The Photovoltaic module used was Rahimafrooz Solar RAS-40W-P. The module specifications are listed in the table 1. The Global Horizontal Solar Radiation data were collected from the Department of Science and Humanities. The setup was installed on the roof

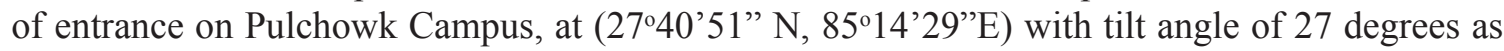
shown in the Fig. 3 [13]. 
4 Impact Study on Power Generation from Photovoltaic System due to Change in Local Irradiance and ........

Table 1: Module specifications

\begin{tabular}{|c|l|}
\hline Model No. & RAS-40W-P \\
\hline Rated Peak Power (Pmax) & $40 \mathrm{~W}$ \\
\hline Rated Voltage (Vmp) & $17.5 \mathrm{~V}$ \\
\hline Rated Current (Imp) & $2.4 \mathrm{~A}$ \\
\hline Short Circuit Current (Isc) & $2.84 \mathrm{~A}$ \\
\hline Open Circuit Voltage (Voc) & $21.5 \mathrm{~V}$ \\
\hline Module Efficiency (\%) & $14.791 \%$ \\
\hline Cell Efficiency (\%) & $18.016 \%$ \\
\hline
\end{tabular}

During the study period, the module was cleaned daily and Pmax of the solar module was measured. The variation in power output of module was signalled by the varying values of Imp and Vmp of both solar modules and recorded into the individual data loggers manufactured using AT89s52 microcontrollers as shown in the Fig. 3. The module temperature was measured using a DS1820 temperature sensor. Data loggers were fed by $12 \mathrm{~V} / 7.8 \mathrm{Ah}$ battery for continuous operation. A $10 \mathrm{~W}$ solar PV module was used to charge the same battery.
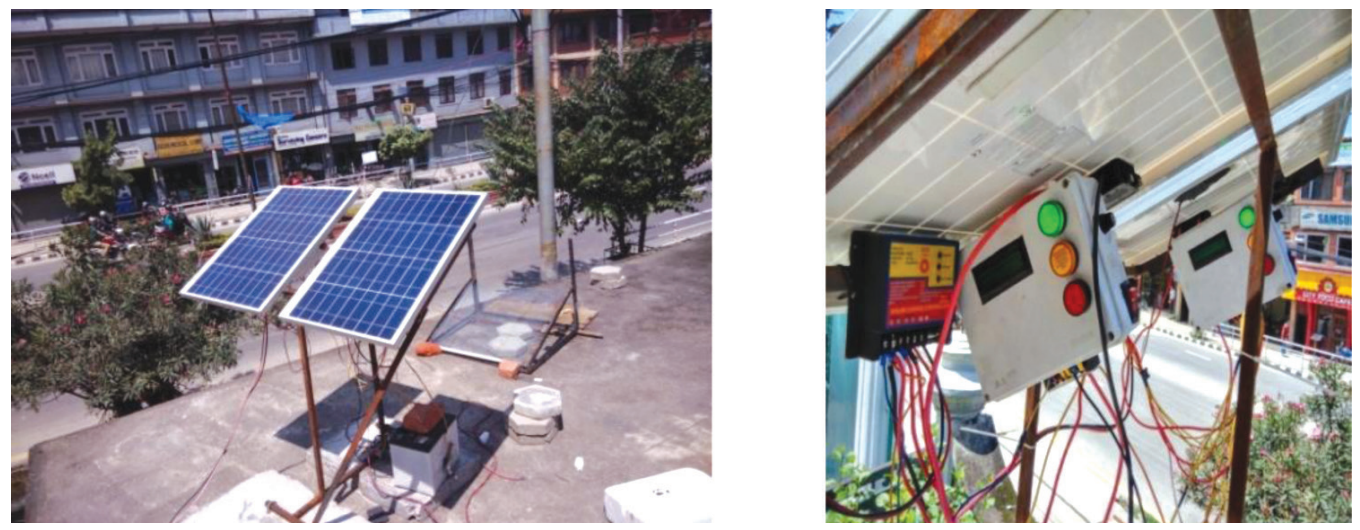

Fig. 3: Experimental Setup for Data Collection

The corresponding system was also simulated using MATLAB. Data for temperature, rainfall and humidity were collected from Department of Hydrology and Meteorology, Kathmandu for the nearest meteorological site at Kathmandu airport whereas solar irradiance was measured at one of the buildings of Central Campus, Pulchowk. The values of Pmax and cell temperature were simulated using diode equation [5] and King's equation [9] respectively.

\section{Design of Experiment}

Design of Experiments (DOE) techniques enables designers to determine simultaneously the individual and interactive effects of many factors that could affect the output results in any design. DOE also provides a full insight of interaction between design elements; therefore, it helps turn any standard design into a robust one. DOE helps to pin point the sensitive parts and sensitive areas in designs that cause problems in output $[11,12]$. 


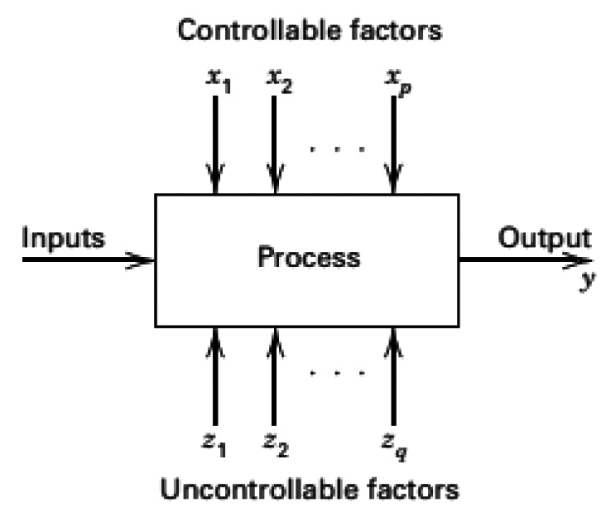

Fig. 4: General model of experiment

The current experiment involves 2 factors namely temperature and irradiance. The maximum and minimum bounds and the centers of the intervals are the experimental points of design. The mathematical model describing the two level full factorial design is shown in equation 1 . The model obtained is a first order polynomial function.

$$
\begin{gathered}
Y=f\left(x_{i}\right)=a_{0}+\sum a_{i} x_{i}+\sum a_{i j} x_{i} x_{j} \\
\mathrm{i} \in \mathrm{N}, \quad \mathrm{j}=\mathrm{N}, \quad \mathrm{i} \neq \mathrm{j}
\end{gathered}
$$

where, $\mathrm{N}$ is set of natural numbers.

The coefficient $\mathrm{a}_{0}$ is the value of the response in the central point of the experiment; considered to be the average response. Coefficient $a_{i}$ is the effect of factor $i$ and coefficient $a_{i j}$ is the effect of the interaction between the factor $\mathrm{i}$ and $\mathrm{j}$. The linear model is validated if the standard deviation is within the acceptable range. The higher standard deviation involves the requirement of higher order factors. In general, a second order model is sufficient. This second order model is shown by the equation 2.

$$
Y=a_{0}+a_{1} x_{1}+a_{2} x_{2}+a_{12} x_{1} x_{2}+a_{11} x_{1}^{2}+a_{22} x_{2}^{2}
$$

Table 2: Data recorded from experiment

\begin{tabular}{|c|c|c|c|}
\hline S. No. & Power(W) & Temperature $\left({ }^{\circ} \mathbf{C}\right)$ & Irradiance $\left(\mathbf{W} / \mathbf{m}^{\mathbf{2}}\right)$ \\
\hline 1 & 42.2735 & 51.38 & 1135.82 \\
\hline 2 & 47.85 & 47.56 & 1050.42 \\
\hline 3 & 41.47 & 45.31 & 272.989 \\
\hline 4 & 16.1343 & 37.56 & 206.712 \\
\hline 5 & 14.3842 & 31 & 253.997 \\
\hline 6 & 16.0598 & 32 & 182.326 \\
\hline 7 & 10.3425 & 30.19 & 164.235 \\
\hline 8 & 9.4737 & 28.5 & 98.676 \\
\hline 9 & 8.7872 & 29.25 & 127.994 \\
\hline
\end{tabular}


6 Impact Study on Power Generation from Photovoltaic System due to Change in Local Irradiance and ........

\begin{tabular}{|l|l|l|l|}
\hline 10 & 8.9245 & 26.25 & 376.848 \\
\hline 11 & 11.997 & 29.31 & 61.044 \\
\hline 12 & 7.9344 & 27.75 & 22.781 \\
\hline
\end{tabular}

A series of recorded data and output are shown in table 2. The research tends to answer the following question.

- What effect does the temperature have on the output of the photovoltaic solar cell?

- What effect does the irradiance have on the output of the photovoltaic solar cell?

- What is the combined effect of the irradiance and temperature?

A relationship was established to verify the effect of temperature and irradiance separately using a DOE (Design of Experiment) method. Bellia et al. [2] used this method to establish the degree of effect on the output due to irradiance and temperature. This approach was used to determine the effect on the study site.

\section{Results}

The Design of Experiment was conducted using the software JMP-10. The software provides extensive statistical tool for analysis of large amounts of data. A 2 factor Design of Experiment was conducted with the output data. The factors are Irradiance and Cell temperature respectively which are the key factors determining the output of solar panel.

DOE was applied on results of Kathmandu to obtain the following correlation results as on table 3

Table 3: Summary of Fit (Kathmandu)

\begin{tabular}{|l|r|}
\hline RSquare & 0.94364 \\
\hline RSquare Adjusted & 0.94356 \\
\hline Root Mean Square Error & 2.99389 \\
\hline Mean of Response & 15.9904 \\
\hline Observations & 3648 \\
\hline
\end{tabular}

Table 4: Effect Tests (Kathmandu)

\begin{tabular}{|l|r|r|r|r|r|}
\hline \multicolumn{1}{|c|}{ Source } & Nparm & DF & $\begin{array}{c}\text { Sum of } \\
\text { Squares }\end{array}$ & F Ratio & Prob>F (P) \\
\hline Temperature & 1 & 1 & 121.2 & 13.5214 & $0.0002^{*}$ \\
\hline Irradiance & 1 & 1 & 124130 & 13848.6 & $<.0001^{*}$ \\
\hline Temperature * Irradiance & 1 & 1 & 52.01 & 5.8028 & $0.0161 *$ \\
\hline Temperature * Temperature & 1 & 1 & 1.41 & 0.1568 & 0.6922 \\
\hline Irradiance * Irradiance & 1 & 1 & 148.31 & 16.5457 & $<.0001^{*}$ \\
\hline
\end{tabular}

The prediction formula is shown in equation 3. From Table 4 it is found that the $\mathrm{P}$ value for the quadratic factor of temperature is greater than 0.1 and hence this factor is not significant. Thus the general equation 2 is reduced to this form. 


$$
\begin{aligned}
\text { Output Power } & =1.05894-0.02958 * T+0.047422 * G-(T-28.87146) \\
& *(G-350.59298) * 0.0013317-(G-350.59298)^{2} * 0.0000063
\end{aligned}
$$

The surface response for the output is shown in the Fig. 5. The surface response indicates a decrease in output power at higher irradiance.

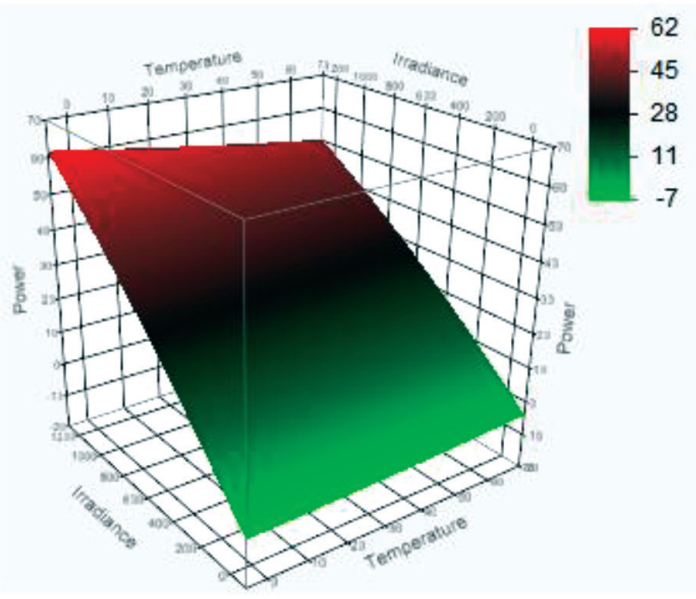

Fig. 5: Output surface plot (Kathmandu)

DOE was applied on results of experiment to obtain the following correlation results as on table 5 .

Table 5: Summary of Fit (Experiment)

\begin{tabular}{|l|r|}
\hline RSquare & 0.676 \\
\hline RSquare Adjusted & 0.665 \\
\hline Root Mean Square Error & 2.132 \\
\hline Mean of Response & 23.22 \\
\hline Observations & 151 \\
\hline
\end{tabular}

Table 6: Effect Tests (Experiment)

\begin{tabular}{|l|r|r|r|r|r|}
\hline \multicolumn{1}{|c|}{ Source } & Nparm & DF & $\begin{array}{c}\text { Sum of } \\
\text { Squares }\end{array}$ & F Ratio & \multicolumn{1}{c|}{$\begin{array}{c}\text { Prob }>\text { F } \\
(\mathbf{P})\end{array}$} \\
\hline Temperature & 1 & 1 & 110.081 & 24.2094 & $<.0001 *$ \\
\hline Irradiance & 1 & 1 & 665.323 & 146.32 & $<.0001 *$ \\
\hline Temperature * Irradiance & 1 & 1 & 30.7022 & 6.7521 & $0.0103 *$ \\
\hline Temperature * Temperature & 1 & 1 & 5.5313 & 1.2165 & 0.2719 \\
\hline Irradiance * Irradiance & 1 & 1 & 4.20665 & 0.9251 & 0.3377 \\
\hline
\end{tabular}

The prediction formula is shown in equation (4). From Table 6 it is found that the P value for the temperature, irradiance and the interaction between temperature and irradiance are significant in the prediction formula. 


$$
\begin{aligned}
\text { Output Power } & =13.2363-0.114763 * T+.0365372 * G+(T-36.73338) \\
& *(G-378.031) * 0.001067
\end{aligned}
$$

The surface response for the output is shown in the Fig. 6. The experimental study illustrated a positive interaction due to combined effect of temperature and irradiance which resulted in overall increase in output power at higher temperatures.

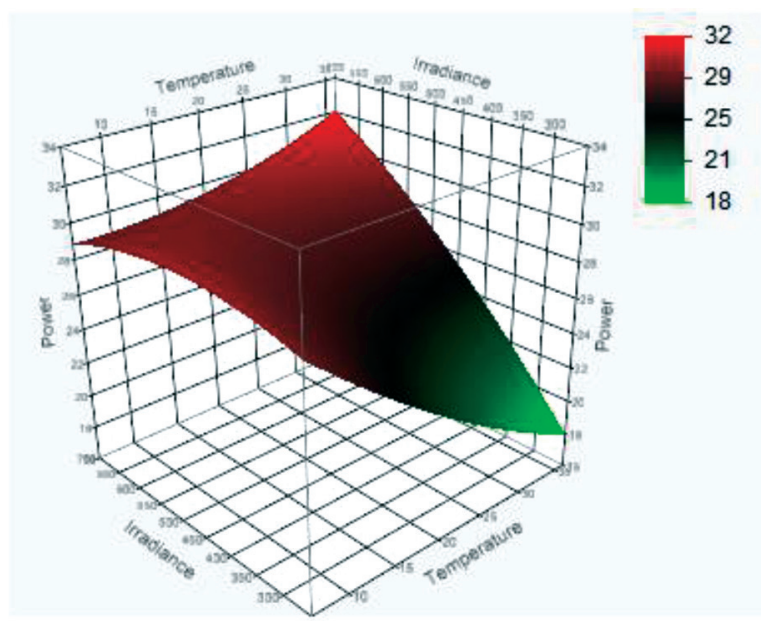

Fig. 6: Output surface plot (Experiment)

\section{Conclusion}

The performance of the PV module is highly influenced by the weather, especially the solar irradiance and the PV-module temperature. In this paper, a model is presented for the PV-module performance calculations where the overall output depends on the linear and quadratic effects of solar irradiance and PV module temperature.

The study showed a negative linear relation between temperature and output power in the studies. The experimental study also concluded a negative impact which was greater than simulation. This may be due to the lack of proper heat dissipation during the experiment. The primary effect was shown by the irradiance which shows the positive effect. This is to be expected as irradiance is the primary input for the output power of the system. The interaction effect due to temperature and irradiance showed a negative impact on the output of simulation while the experiment showed a small positive impact. The quadratic factor for temperature and irradiance had shown negligible effect on the overall output.

\section{Acknowledgement}

The experiment was supported by Nepal Academy for Science and Technology (NAST) for the study "Dust Accumulation Effects on Efficiency of Solar PV Modules for off Grid Purpose". Meteorological data were provided by Department of Hydrology and Meteorology, Kathmandu. Robotics Club, Institute of Engineering deserves the special gratitude for their help during the research period. 


\section{References}

[1] Barker G and Norton P (2003), Predicting Long Term Performance of Photovoltaic Arrays using Short Term Test Data and Annual Simulation Tool. Solar 2003 Conference: America's Secure Energy.

[2] Bellia A, Ramdani Y, Moulay F and Medles K (2013), Irradiance and Temperature Impact on Photovoltaic Power by Design of Experiments. REVUE ROUMAINE DES SCIENCES TECHNIQUES-SERIE ELECTROTECHNIQUE ET ENERGETIQUE 58(3): 284-294.

[3] Duffie JA and Beckman WA (2013), Solar Engineering of Thermal Process, 4th ed. Wiley.

[4] Evans D (1981), Simplified Method for Predicting Photovoltaic Array Output. Solar Energy 27: $555-560$.

[5] Francisco M and Longatt G (2005), Model of Photovoltaic Module in Matlab. II CIBELEC, 1-5.

[6] Hegedus S and Luque A (2003), Handbook of Photovoltaic Science and Engineering. John Wiley \& Sons Inc.

[7] Hove T (2000), A Method for Predicting Long Term Average Performance of Photovoltaic Systems. Renewable Energy 21: 207-229.

[8] Kerr M and Cuevas A (2003), Generalized Analysis of the Illumination Intensity vs Open Circuit Voltage of PV. Solar Energy 76: 263-267.

[9] King DL (1996), Photovoltaic Module and Array Performance Characterization Method for all System Operating Conditions. NREL/SNL Photovoltaics Program Review, Sandia National Laboratories, Lakewood, CO.

[10] Mondol JD, Yahonis Y, Smyth M and Norton B (2005), Long Term Validated Simulation of a Building Integrated Photovoltaics System. Solar Energy 78: 163-176.

[11] Montgomery DC (2012), Design and Analysis of Experiments. John Wiley \& Sons Inc.

[12] NIST/SEMATECH (2012), e-Handbook of Statistical Methods, Retrived from http://www.itl. nist.gov/ div898/handbook/

[13] Paudyal BR and Shakya SR (2016), Dust Accumulation Effects on Efficiency of Solar PV Modules for Off Grid Purpose: A Case Study of Kathmandu. Solar Energy 135: 103-110

[14] Soto WD, Klein S and Beckman W (2006), Improvement and Validation of a Model for Photovoltaic Array Performance. Solar Energy 80: 78-88.

[15] Widalys DS (2004), Improvement and Validation of a Model for Photovoltaic Array Performance. Solar Energy Laboratory, University of Wisconsin, Madison.

[16] Zhoua W, Yang H and Fang Z (2007), A Novel Model for Photovoltaic Array Performance Prediction. Applied Energy 84: 1187-1198.

[17] (2016), Retrieved from PVeducation: http://pveducation.org/ 